\title{
Digital game-based learning for D\&I: conceptual design of an educational digital game Chuzme
}

\author{
Elena Shliakhovchuk, PhD ${ }^{a}$, Adolfo Muñoz García, $\mathbf{P h D}{ }^{\mathbf{b}}$ \\ ${ }^{a}$ Universitat Politècnica de València (UPV), Spain, shelvik@gmail buniversitat Politècnica de \\ València (UPV), Spain, amunyoz@upvnet.upv.es
}

\begin{abstract}
There is a demand for tools facilitating intercultural, diversity and inclusion (D\&I) education. Video games are one of the most advanced new media technologies, so it is only natural to suppose that they can offer remarkable possibilities for fostering learning in the area of intercultural, D\&I education. This article explores theoretical guidelines in the design of Chuzme, a serious educational game that focuses on raising cultural selfawareness, the acknowledgement of cultural bias, and aims to generate positive attitudes towards migrants, refugees and expatriates amongst its players and to train to be an inclusive leader. It is hoped that this will serve as a useful reference to guide the development of similar titles in the future.
\end{abstract}

Keywords: Educational digital games, refugees, diversity and inclusion (D\&I), game-based learning

\section{Introduction}

The science of learning has shown that humans learn more effectively via active learning than via passive learning (Schank, 1995). The characteristics of active and engaged learning are necessary components for education in today's world because it allows students to employ critical thinking skills, analyse, evaluate and synthesise in order to make decisions and determine the course of their actions (Dickey, 2005). The five-year compound annual growth rate for game-based learning products on the planet is $20.2 \%$, and revenues are expected to double to $\$ 8.1$ billion by 2022 (Adkins, 2017).

A digital game is an effective resource to make students engage with a complex subject such as cultural studies and D\&I education (Shliakhovchuk, 2019). In this regard, serious games (SG), i.e. those not primarily meant to entertain, offer unique possibilities for creating educational tools for intercultural communication. SGs allow experimentation in 
controlled environments, something that can, for example, be useful for simulating interactions between culturally different participants. SGs can also be used as persuasive tools to influence players' ideas and behaviours.

\section{ATMSG model as a background of Chuzme design}

Several frameworks have been developed to cater for the development of video games in both general and particular cases (e.g. MDA, DPE) and many researchers have attempted to define the structure of video games (Harteveld, 2011; Ralph \& Monu, 2015; Schell, 2008 among others).

When designing Chuzme, several models were reviewed to identify the one best suited for the project. After careful consideration, to support Chuzme's game design phase, the ATMSG model (Callaghan, McShane, Eguíluz, \& Savin-Baden, 2018; Carvalho et al., 2015) was chosen for its complex and dynamic view on serious games, while the overall design process was guided by the serious instructional design process, developed by Becker \& Parker (2011) as a combination of simulation design (SD), game design (GD) and instructional design (ID). The serious instructional design process consists of six phases. The first phase, "Discovery", encompasses the needs analysis and rough outlines for framing the project in its proper context. This phase identifies the game's main objectives and premise and also develops a general understanding of who the game's intended users are, how these users will obtain what they need, and how one can know that they have. During the second phase, "Research", materials and facts are gathered, and limitations and original systems are defined. Figure 1 summarises models.

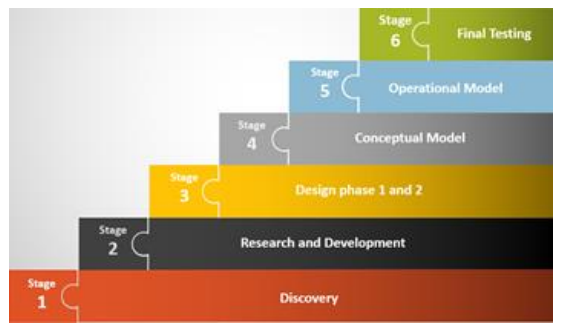

Fig.1 Game design process (adapted from Becker \& Parker (2011)

The third phase, "Design phase 1 and 2", is where the game takes shape. Here, the Activity Theory-based Model's perspective is used. In this model, educational SGs are intricate, dynamic systems composed of three main activities - playing, learning, and teaching — and they have two subjects - the learner (player/student) and the instructor (responsible for game design and development). These subjects have different motives (e.g. have fun, fulfil 
a course requirement, or engage students). ATMSC's hierarchical structure focuses on different levels of detail, providing a flexible tool to analyse and design interaction and gameplay, dividing activities into actions and the game itself into smaller pieces (Callaghan et al., 2018; Carvalho et al., 2015). Figure 2 describes the five-step approach to applying ATMSC.

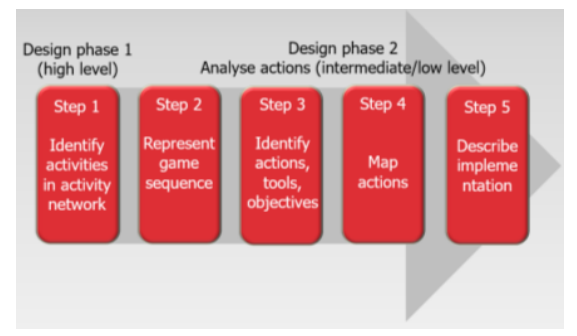

Fig. 2 Five-step approach for applying ATMSC (adopted from (Callaghan et al., 2018; Carvalho et al., 2015).

During the fourth phase, "Conceptual model", detailed design documents are elaborated (pre-programming). Then follows the fifth phase, "Operational model", which is where the programming of the game takes place. The sixth and final phase, "Final testing", may be listed as a separate phase of the model, but the testing should actually start as soon as the first playable prototype is ready. These phases propose an overarching framework comprising conceptual and technical frameworks for enhancing intercultural skills.

There is the temptation for beginning game developers to jump right into a project and start writing code and drawing pictures. This is a mistake because unless there is a clear direction for the project, their work will be poorly focused. It is hard to design a fullfledged game that tackles intercultural issues and is a huge amount of fun at the same time. Still, it is possible to deal with these issues through short games that are effective and inexpensive tools. Chuzme is meant to be one such game, and this article takes a detailed look at the conceptual design of this game.

\section{Chuzme game design}

Educating for intercultural education demands learning approaches and environments that require the development of systems thinking and problem-solving. Shen, Wang, Ritterrfild, (2009) analysed America's Army-Operations (2002), Objection (2008), Re-Mission (2006), Electrocardiogram (2008), Londoner (2007), Hate Comes Home (2008), and Darfur is Dying (2006) and recognised that narrative-related elements such as character and dialogues, humour, and social interaction together with sophisticated and high-quality presentation and a gameplay structure with complexity and diversity bring a certain level of 
enjoyment while playing educational games. Romero, Usart, \& Ott (2015) added that in order to facilitate learning and skill development, games should contain authentic and enriched learning scenarios, game rules with endogenous and exogenous reinforcement, and a certain level of competition. Thus, when designing a game with a high potential for promoting the development of complex systems thinking and facilitating a systemic understanding of D\&I issues, complexity is an element that should definitely be included.

\section{The backstory of Chuzme}

A simple and easy-to-understand backstory was designed to engage and immerse the learner in the game and to offer a technology-enhanced constructivist setting endowed with virtual manipulation. The emphasis lies on comprehension, observation, problem-solving abilities, exploration and thought. Chuzme invites players to explore the settings, objects and characters within the game from the first-person perspective.

In Chuzme, the player is a talented young entrepreneur who applied with his Big Idea to the biggest and best-known accelerator, Y Combinator from Silicon Valley, who received notification from it that his Big Idea passed the initial level of selection and now $\mathrm{Y}$ Combinator would like to meet the team behind the Big Idea. If the team is accepted, it will fly to the San Francisco Bay Area to spend the next three months developing their ideas and business plans. Y Combinator offers $\$ 120,000$ for a seven per cent share of the company, legal assistance, group events featuring influential speakers such as the CEOs of Google, PayPal, etc. The climax is Demo Day when the team presents their Big Idea to the 450 deep-pocketed invitation-only investors.

\section{The game mechanics of Chuzme}

The game starts when the player receives notification from Y Combinator that his Big Idea has been accepted for further development. The next step is to present a team that stands behind the Big Idea. Y Combinator notes that the people in the team are often more important than the idea itself, which tends to change significantly during the accelerator process. The most successful teams benefit economically and educationally when they are culturally and gender diverse. Consequently, the objective of the game is to build a culturally and gender-diverse team of four people of $\mathrm{C}$-level talent and to provide equal opportunities for immigrants, refugees and expatriates of both genders. After the objective is explained, the player is put into a city co-working place where they need to pick the team members from a group of people, basing his choice on the candidates' profiles and assuming that they are all high-quality professionals in different stages of their lives that somehow contributed to this Big Idea.

In the first level of the game, the player has to rely on his "gut feeling" to choose 10 people (out of 32) whom he thinks might be a good fit for the Dream Team (Picture 1). The gamer 
is offered a free in-game hints on what is gender-balanced working environment, what is diversity and why it is all important. The choice is done under 60 second pressure. The pictures of people are randomly generated from the https://thispersondoesnotexist.com/.

Ideally, if the player is male: among ten chosen candidates, at least five women should be included. If the player is a female among ten chosen candidates should be at least five males. If less, in-game hints about diversity and inclusion will be offered to read. A player starts a level with some complimentary points. If the player makes a good gender balance during this level, he is given points for keeping gender balance and ethnical diversity at the end of the

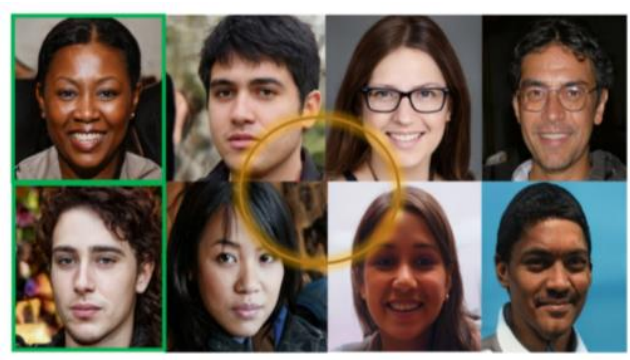

Pic.1 First level of the game "Gut reaction"

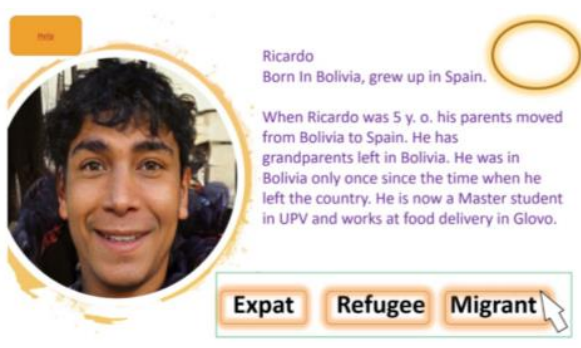

Pic. 2 Second level of the game "Expat bubble or Migrant struggle?"

level. Points are discounted if there is no gender balance or ethnical diversity. At the end of the level, he is shown a leader board of other people who passed the level before him and who make gender-balanced and ethnically diverse choices in the shortest period of time. The personal score is displayed, and the level of gender and diversity in the team. The option to replay the level is offered as well.

During the second level "Expat bubble and Migrant struggle?", 10 shortlisted candidates show the short story of their lives, and the player has two missions during this level. The first mission is: to place the candidates into refugee, migrant or expatriate selection based on their background that is offered as a written file (Picture 2). At the beginning of the level, a player is offered a free in-game hint to help to distinguish on who is refugee, migrant or expatriate before starting the selection. If he can distinguish well, he is given points for each correct placement. If a player is mistaken, points are discounted from his score. The option to correct file placement is offered, but the correct answer will not bring 10 points. After the first mission is activated, the in-game hinds could be consulted as well, but now they will cost 3 points per each link consultation. The first mission is over when all profiles are sorted correctly. To take a decision on the profile, 20 seconds are given, thus, the shortest first mission could last 200 seconds. During the second mission, a player needs to choose 6 candidates out of 10 who will be invited for a personal interview keeping in mind the gender and cultural diversity. Thirty seconds are given to accomplish the mission. 
At the end of the level, a leader board of people who make the best choice in the shortest period of time is presented. The personal score, gender balance and diversity level are displayed as well.

The third level called "Tell me who your friends are, and I'll tell you who you are" and its mission is to ask the shortlisted candidates four questions from a list of questions provided and choose three perfect candidates to include in the Dream Team based on their answers. There are three categories of questions: general information about a person, sensitive personal questions, work experience related questions. Questions cover a wide range of bias. The player must ask four questions from all three categories. A player can listen to the answers from all candidates or only from the ones she/he selects. There is no time pressure at this level. But a player can't replay the answers from the previous questions: one question -> answers, second question $->$ answer, etc. Audio files with the answers to the questions are provided. At the end of the level, when four questions are being asked, a player is invited to form the Dream Team.

The game ends (successfully) when the diverse team is formed: two female and two male, one refugee, one migrant and one expat. The player is notified that he receives four tickets to fly to the San Francisco Bay Area and the amount of $\$ 120,000$ has been transferred into its account. There is also an option to play a secret bonus level before quitting the game. However, this option is added to check if a player liked the game and would like to go on with more playing. If the player fails to form the gender- and diversity-balanced team within the time allotted, a player is notified that Y Combinator bars him/her from any future participation. There is a choice to restart the game.

\section{The Interaction Design}

Chuzme uses storyline, characters, gameplay, and behavioural procedures as mechanisms to influence mediating variables. The game includes situations in which players could find themselves, problems they could encounter, and their solution. The emotions that a player draws from the personal experience of playing are a sense of achievement (mastery of ingame skills), a sense of empowerment (performing acts that cannot be performed in real life), and a sense of experimentation (taking a certain role) (Salmond, 2016). The fact that the game is educational means it needs to be adapted to everybody, including those who define themselves as non-gamers, which in turn means developing easily accessible and simple-to-control game. Ideally, gameplay should not exceed 5-20 minutes (Baaden et al., 2018).

\section{The Gameplay}

Every effort was made to let players gather information through clear visual and auditory media that provides information. For example, players learn about people in front of them 
by listening to their story, rather than by reading (audio file), even though the game provides some material in the form of text and photographs.

\section{In-game hints for student guidance}

Chuzme allows players to make progress regardless of their previous knowledge level or background thanks to its in-game hint system. Chuzme includes hints that are delivered when requested and at a cost to the player established by the designer. Some hints such as those that help users deal with the interface are provided at no cost. These hints guide players who need it but do not disturb those who can do without. Providing these breadcrumbs to players broadens the audience by including those that might otherwise have found the game confusing.

\section{Measure the transference of knowledge and assessment design}

Student assessment in educational games, designed as an explicit representation, possesses great potential for tracking and assessing students' learning outcomes if to make comparison with less interactive educational media. Educators highlight and score relevant actions, generate feedback, identify and rectify inaccurate assumptions, which is essential in educational games during the de-briefing stage after the game is played (Garris, Ahlers, \& Driskell, 2002).

The nature of the subject matter and the basic design of the game gives all that is needed for in-game assessments, although a determination of whether or not the player has met the performance objectives will happen outside the game. Measuring what players are learning is straightforward and is accomplished in several possible ways: 1) in-game survey at the beginning of the game (questionnaire about player's background, later to be used to evaluate personal bias and cultural stereotypes) and 2) through group or individual interviews after the gameplay experience. However, an instructor is free to choose any methodology of introducing this game in class, pre and post knowledge assessment.

Moreover, data is collected from in-game traces to see if the game is having an impact on the attitudes of the players. The feedback generated from the in-games traces is expected to enhance learner's awareness of their own bias and stereotypes, to improve the alignment between their expressed behaviour and intended behaviour. Participants' in-game traces can be rated, annotated and evaluated by educators and contrasted with participants' own opinions during group or individual interviews.

As a result, the holistic approach to research and design, and a mix of different methods for data collection and analysis lead to the valuable measuring of the knowledge transfer to the player. This is crucial for educational games; however, to date, few games have attempted to do so. 
It's worth noting that Chuzme is not supposed to be a standalone title but to be integrated as an educational tool. As I was mentioned before, the role of the teacher is very important with respect to if and how this game becomes a learning process. In other words, the teacher is to provide elements of analysis and reflection that allow learning to happen using the contents of the game.

\section{Implementation Details}

When designing a video game, the right platform and format choice is the key. Using casual gaming approach broadens the pool of potential players. Thus, concerning the technical aspect, Chuzme could be implemented into Unity 3D, a cross-platform game engine that offers advanced lighting and rendering options, pipeline optimisation, physics management, built-in support for spatialised audio, multitasking, complex animations and networking. Interaction implements a client-server architecture in which the server handles the simulation state and controls the projected screen, and the clients are the players' devices. Finally, an AR Foundation Package could be used as a software library that can be integrated intoUnity, thus supporting the game deployment on different mobile platforms (iOS, and Android). For accelerating the development of the app in Unity for the HoloLens AR glasses, Microsoft Mixed Reality Toolkit will be used.

Chuzme intends to make use of visual and sound channels. Otherwise, the player quickly becomes overloaded with one modality usage and will be lost. Sound effects and music drive interest or increase scenario effects (Baaden et al., 2018). Interesting modality to develop for $\mathrm{AR}$ solution is touch (e.g. manipulation by hand with augmented reality applications). The new HoloLens 2 has been announced this year as an evolution of the previous model with tracking of both hands and fingers to allow the direct manipulations of AR figures with bare hands.

\section{Validation}

The first informal evaluation of the concept and game mechanics presented as a recorded video clip happened during Sietar Congress 2019, held in Leuven, Belgium, from 30th of May till 1st of June (Sietar is a Society for Intercultural Education, Training and Research). Ten leading experts from intercultural, diversity and inclusion fields were asked to see the video clip and to share their viewpoints on the concept, dynamics and mechanics of the game, possible inconsistencies and disharmony of the flow of the game. At the end of a watching session, the recorded video was discussed, rated, and evaluated by expert observers. To summarize user feedback and reactions, it is worth noting that 10 out of 10 experts highlighted: 1) strong concept of Chuzme; 2) the capability of Chuzme to engage the user in meaningful learning; 3) saw the game as a possible tool to practice diversity and inclusive teambuilding; 4) described a concept of the design of a game as thoughtprovoking. Nine out of 10 experts pointed to the potential of the game to facilitate a critical 
reflection on the bias and stereotypes. The experts unanimously stated as possible application domains of Chuzme in intercultural and D\&I education.

\section{Conclusions}

Developing an educational game is a maltifaced and challenging endeavour due to its having to satisfy experts and novices alike while the integration of gameplay and learning content (Kelly et al., 2007). The logically consistent, well-designed conceptual model called Activity Theorybased Model of Serious Games (ATMSG) was used as a theoretical guideline in the designing of Chuzme which helped to identify the main elements for improving the educational outcomes expected of the game.

A description of various mechanisms--such as storyline, characters, gameplay, and behavioural procedures-was provided to help understand the mediating variables this video game is meant to influence and to show how these elements are interconnected and how they contribute to achieving the desired learning outcomes. Prior to constructing the video game, we conducted formative work to make sure that the game's characters, the storyline, problems, and solutions are realistic and appealing to the intended audience. Behaviouralchange components that are embedded in the gameplay and help advance the storyline, such as goal setting and goal review, were tested with professionals of the field. Chuzme enables the player to make choices for their character and to observe the short- and longerterm consequences of their choices for themselves and others. Connecting goals to personal values, providing choice and performance-related feedback and structuring the game in levels that are gradually challenging all aim to enhance the intrinsic motivation of the player and help to see the big picture. The use of in-game measurements and analytics allows the instructor to monitor the learner's retention and to check whether the intended learning outcomes are achieved.

As future work, completing the implementation of Chuzme and a game-prototyping with crude interface sketches and playable prototypes are planned. Quantitative and qualitative approaches to be elaborated to perform a thorough evaluation of the game and to demonstrate the significant advantages of using video game in D\&I education. Further evaluation will also serve for evaluating the efficacy of the chosen reference framework in guiding the design of D\&I games. The game design will surely evolve after further testing, and the impact of those changes will naturally be evaluated, including by the means of ingame analytics.

It is hoped that this guideline will serve as a helpful reference to guide the design and development of similar titles in the future. But of course, there is not a "one-game-fits-all" 
approach that will assist equally students with gaining requisite skills. Clearly, it is important to continually seek methods, strategies and exemplars conducive to designing optimal digital game-based learning environments (Dickey, 2005).

\section{References}

Adkins, S. (2017). The 2017-2022 Global Game-based Learning Market. Retrieved from http://seriousplayconf.com/wp-content/uploads/2017/07/Metaari_20172022_Global_Game-based_Learning_Market_Executive_Overview.pdf

Baaden, M., Delalande, O., Ferey, N., Pasquali, S., Waldispühl, J., \& Taly, A. (2018). Ten simple rules to create a serious game, illustrated with examples from structural biology. PLOS Computational Biology, e1005955. https://doi.org/10.1371/journal.pcbi.1005955

Becker, K., \& Parker, J. R. (2011). The guide to computer simulations and games. Wiley Pub.

Callaghan, M., McShane, N., Eguíluz, A. G., \& Savin-Baden, M. (2018). Extending the Activity Theory Based Model for Serious Games Design in Engineering to Integrate Analytics. International Journal of Engineering Pedagogy (IJEP), 8(1). https://doi.org/10.3991/ijep.v8i1.8087

Carvalho, M. B., Bellotti, F., Berta, R., De Gloria, A., Sedano, C. I., Hauge, J. B., ... Rauterberg, M. (2015). An activity theory-based model for serious games analysis and conceptual design. Computers \& Education, 87, 166-181. https://doi.org/10.1016/J.COMPEDU.2015.03.023

Dickey, M. D. (2005). Engaging by design: How engagement strategies in popular computer and video games can inform instructional design. Educational Technology Research and Development, 53(2), 67-83. https://doi.org/10.1007/BF02504866

Garris, R., Ahlers, R., \& Driskell, J. E. (2002). Games, Motivation, and Learning: A Research and Practice Model. Simulation \& Gaming, 33(4), 441-467. https://doi.org/10.1177/1046878102238607

Harteveld, C. (2011). Triadic Game Design: Balancing Reality, Meaning and Play (1st ed.). Springer Publishing Company. Retrieved from https://dl.acm.org/citation.cfm?id=1972536

Kelly, H., Howell, K., Glinert, E., Holding, L., Swain, C., Burrowbridge, A., \& Roper, M. (2007). How to build serious games. Communications of the ACM, 50(7), 44-49. https://doi.org/10.1145/1272516.1272538 
Ralph, P., \& Monu, K. (2015). Toward a Unified Theory of Digital Games. The Computer Games Journal, 4(1-2), 81-100. https://doi.org/10.1007/s40869-015-0007-7

Romero, M., Usart, M., \& Ott, M. (2015). Can Serious Games Contribute to Developing and Sustaining 21st Century Skills? Games and Culture, 10(2), 148-177. https://doi.org/10.1177/1555412014548919

Salmond, M. (2016). Video game design : principles and practices from the ground up (1st ed.). Fairchild Books.

Schank, R. C. (1995). What We Learn When We Learn by Doing. Retrieved from http://cogprints.org/637/

Schell, J. (2008). The art of game design: a book of lenses. Elsevier/Morgan Kaufmann.

Shen, C., Wang, H., Ritterrfild, U. (2009). Serious Games and Seriously Fun Games: Can They Be One and the Same? In V. P. Ritterfeld,U., Cody, m. (Ed.), Serious Games Mechanisms affects (pp. 70-84). Routledge. https://doi.org/10.4324/9780203891650-12

Shliakhovchuk O. (2019). Cultural literacy acquisition through video game environments of a digitally born generation. Universitat Politecnica de Valencia. Retrieved from https://www.upv.es/entidades/EDOCTORADO/menu_865673i.html 